\title{
Changes in the Rat Blood Lymphocyte Composition in the Dynamics of Acute Irreversible Mesenteric Ischemia
}

\author{
Zoya A. Artamonova, $\mathrm{PhD}^{1}$; Evgeny V. Namokonov, $\mathrm{PhD}, \mathrm{ScD}^{1}$; Marina A. Darenskaya, \\ $\mathrm{PhD}, \mathrm{ScD}^{2}$; Natalya V. Semenova, $\mathrm{PhD}, \mathrm{ScD}^{2}$; Lyubov I. Kolesnikova, PhD, ScD, \\ Academician of the RAS ${ }^{2}$; Sergey I. Kolesnikov, $\mathrm{PhD}, \mathrm{ScD}$, Academician of the RAS ${ }^{2}$ \\ ${ }^{I}$ Chita State Medical Academy, Chita, the Russian Federation \\ ${ }^{2}$ Scientific Centre for Family Health and Human Reproduction Problems, Irkutsk, the Russian Federation
}

\begin{abstract}
The aim of this research was to study the levels of the main populations of blood lymphocytes in various stages of acute irreversible arterial mesenteric ischemia in an experiment.

Methods and Results: Acute mesenteric ischemia (AMI) was simulated by ligating the cranial mesenteric artery at the mesenteric root. The study was performed on white non-linear male rats, weighing $200 \pm 25 \mathrm{~g}$. According to the research protocol, the animals were divided into 3 groups depending on the time of compression of the general blood flow ( 3 hours $(\mathrm{n}=10), 6$ hours $(\mathrm{n}=10)$, and 8 hours $(\mathrm{n}=10))$. As a comparison, we used data from 30 animals (before artery ligation). The main populations and subpopulation structure of lymphocytes (total number of lymphocytes, CD3+ T cells, CD4+ T cells, CD8+ T cells, B cells, NK cells, and the $\mathrm{CD} 4+/ \mathrm{CD} 8+$ ratio) were evaluated.

We found that the content of lymphocytes in the venous blood of rats has been directly dependent on the time of ischemia. After 3 hours of AMI development, a statistically significant decrease in the total number of lymphocytes and an increase in the content of CD3+ T cells, CD4+ T cells, CD8+ T cells, and the CD4+/CD8+ ratio occur. After 6 hours of AMI development, a statistically significant decrease in the total number of lymphocytes was persisted. The number of CD8+ T cells decreased, while the level of $\mathrm{CD} 4+\mathrm{T}$ cells increased with increasing the $\mathrm{CD} 4+/ \mathrm{CD} 8+$ ratio. In this period, a significant drop in the number of $\mathrm{B}$ cells was noted. After 8 hours of AMI development, more pronounced changes were observed concerning various populations of lymphocytes: a statistically significant decrease in the total number of lymphocytes, CD3+ T cells, CD4+ T cells, CD8+ T cells, $\mathrm{B}$ cells, and NK cells. It should be noted that during this period, the CD4+/CD8+ ratio increased by more than 3 times relative to the initial indicator.

Conclusion: The significant decrease in the number of venous blood lymphocytes can be used to predict the severity of the disease in a comprehensive examination of patients with AMI. (International Journal of Biomedicine. 2020;10(3):270-273.)
\end{abstract}

Key Words: acute mesenteric ischemia $\bullet$ rats $\bullet$ immunity $\bullet$ lymphocytes

\section{Introduction}

Acute mesenteric ischemia (AMI) is typically defined as a sudden interruption of the blood supply to a segment of the small intestine, leading to ischemia, cellular damage, intestinal necrosis, and eventually patient death if untreated. ${ }^{(1,2)}$ AMI develops with occlusive changes in visceral blood flow, caused

*Corresponding author: Marina A. Darenskaya, PhD, ScD. Scientific Centre for Family Health and Human Reproduction Problems, Irkutsk, the Russian Federation. E-mail: marina darenskaya@inbox.ru by arterial embolism, arterial and/or venous thrombosis, as well as due to non-occlusive blood flow disorders against the background of reduced cardiac output. ${ }^{(3,4)}$ In AMI, such factors as arterial thrombosis and thromboembolism are the leading causes leading to occlusion of the visceral branches of the abdominal aorta and intestinal infarction. ${ }^{(5)} \mathrm{AMI}$ is still one of the most severe pathologies in emergency surgery and accounts for about $1 \%-2 \%$ of gastrointestinal diseases and about $0.1 \%$ $0.4 \%$ of emergency surgical pathology, and the incidence rate tends to increase. ${ }^{(2,4,5)}$ There is a high intrahospital mortality rate of this disease - at the level of $60 \%-80 \%{ }^{\left({ }^{(}\right)}$The main reason for the high lethality of AMI is the difficulty of its 
timely diagnosis even in specialized medical institutions The latter may be due to extremely large numbers of antigens and the duration of their contact with the intestinal mucosa. and, as a result, later and ineffective operational manual. ${ }^{(3,5)}$ As a result, it is highly relevant to study the pathophysiological processes that accompany AMI, with the subsequent creation of new methods of diagnosing and treating this pathology. ${ }^{(7,8)}$

It is common knowledge that the gastrointestinal tract performs not only digestive but also immune functions, while about $80 \%$ of all immunocompetent cells of the body are localized in the intestinal mucosa. The immunocompetent cells of the gastrointestinal tract belong to the lymphoid tissue, which, in turn, is a component of the unified lymphoid system and represents the largest department of the immune system by volume. ${ }^{(9)}$ The latter may be due to extremely large numbers of antigens and the duration of their contact with the intestinal mucosa. The immune system of the gastrointestinal tract consists of inductive (Peyer's plaques, vermiform process, solitary follicles) and effector (lamina propria and epithelial cells of the intestinal mucosa) zones. ${ }^{(10)}$ In the first zone, the first contact of lymphocytes with antigen occurs; in the second zone, immunoglobulin synthesis by B lymphocytes and cytokine production by monocytes/ macrophages, CD3 + T cells, and NK cells perform. ${ }^{(9)}$ It is likely that acute disorders occurring in AMI already in the early stages can lead not only to a violation of digestive function but cause a deep imbalance in the immune system.

In this regard, the aim of this research was to study the levels of the main populations of blood lymphocytes in various stages of acute irreversible arterial mesenteric ischemia in an experiment.

\section{Material and Methods}

The study was performed on white non-linear male rats, weighing $200 \pm 25 \mathrm{~g}$. The experiment was conducted on the basis of a certified vivarium of the Chita State Medical Academy. The animals were kept in standard conditions with free access to water and food. Right after laparotomy, AMI was simulated by ligating the cranial mesenteric artery at the mesenteric root, and then the wound was sutured.(11) Termination of the blood flow through the artery was controlled visually: blanching of the artery distal to the ligation site, the desolation of the marginal vessels of the small intestine, and the cessation of their pulsation. Then, at certain time intervals, the relaparotomy was performed, blood was collected, and the animals were withdrawn from the experiment.

According to the research protocol, the animals were divided into 3 groups depending on the time of compression of the general blood flow ( 3 hours $(n=10), 6$ hours $(n=10)$, and 8 hours $(n=10))$. As a comparison, we used data from 30 animals (before artery ligation). The blood for the study was collected before the artery was ligated (initial data), after 3,6 , and 8 hours. The blood was delivered to the laboratory within 15 minutes. The main populations and subpopulation structure of lymphocytes (total number of lymphocytes, CD3+ T cells, CD4+ T cells, CD8+ T cells, B cells, NK cells, and the $\mathrm{CD} 4+/ \mathrm{CD} 8+$ ratio) were evaluated using the standard method of direct immunofluorescence staining of whole blood using the VersaLyse/IOTest 3 Fixing solution lysing/fixing solution (Beckman Coulter) and the IOTest Anti-Rat monoclonal antibodies panel (Beckman Coulter). The control samples were incubated with immunoglobulins labeled with fluorochromes (FITC, PC7, APC) of the corresponding isotype - mouse IgG1, IOTest (Beckman Coulter). Cytofluorometry was performed on the "Cytomics FC-500" flow cytofluorometer (Beckman Coulter, USA), registering a total of at least 10,000 events. The data was analyzed using the CXP Cytometer (Beckman Coulter) program. Absolute numbers (the number of cells in 1 $\mathrm{mcL}$ of venous blood) were used as units of measurement for these parameters.

The operations and all manipulations with animals were performed using general anesthesia, and euthanasia - by overdosing on drugs for anesthesia, taking into account the provisions regulated by ethical standards. Work on the animals was done in compliance with the principles of the Helsinki Declaration on the humane treatment of animals, stated in normative documents of the European community(86/609/ EU), Manual on Experimental (Preclinical) Study of New Pharmacological Substances, and "Good laboratory practice" (MHRF Order No. 708H dated 23.08.2010). The study was approved by the Ethics Committee of the Chita State Medical Academy.

Statistical analysis was performed using the Statistica 6.0 software package (Stat-Soft Inc., USA). The normality of distribution of continuous variables was tested by the Kolmogorov-Smirnov test with the Lilliefors correction and Shapiro-Wilk test. Baseline characteristics were summarized as frequencies and percentages for categorical variables. Group comparisons with respect to categorical variables were performed using chi-square tests or, alternatively, Fisher's exact test. A probability value of $P \leq 0.05$ was considered statistically significant.

\section{Results and Discussion}

The analysis of the concentrations of the main populations of lymphocytes in the AMI development dynamics showed the following changes.

After 3 hours of AMI development, we found a statistically significant decrease in the total number of lymphocytes by $40.65 \%(P<0.05)$ and an increase in the number of CD3+ T cells by $41.2 \%(P<0.05)$ compared to the initial data. With an increase in the number of CD4+ T cells by $50.96 \%(P<0.05)$, there was a simultaneous increase in the number of $\mathrm{CD} 8+\mathrm{T}$ cells by $32.7 \%(P<0.05)$, leading to an increase in the $\mathrm{CD} 4+/ \mathrm{CD} 8+$ ratio by $71.43 \%(P<0.05)$. No significant changes were detected for B cells and NK cells $(P>0.05)$ (Fig. 1).

After 6 hours of AMI development, a statistically significant decrease in the total number of lymphocytes by $49.5 \%(P<0.05)$ relative to the initial data was found. The level of CD4+ T cells increased by $55.63 \%(P<0.05)$, while the number of $\mathrm{CD} 8+\mathrm{T}$ cells decreased by $26.23 \%(P<0.05)$, and the $\mathrm{CD} 4+/ \mathrm{CD} 8+$ ratio increased by $88.1 \%(P<0.05)$. In this period, there was also a significant drop in the number of $\mathrm{B}$ cells by $71.29 \%(P<0.05)$ compared to the initial data (Fig. 2$)$. 


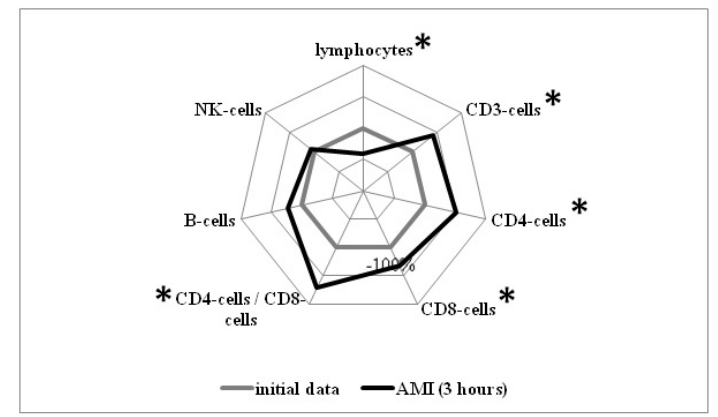

Fig. 1. Changes in blood lymphocyte populations after 3 hours of AMI (*-statistically significant differences compared to the initial data (values are taken as 100\%)).

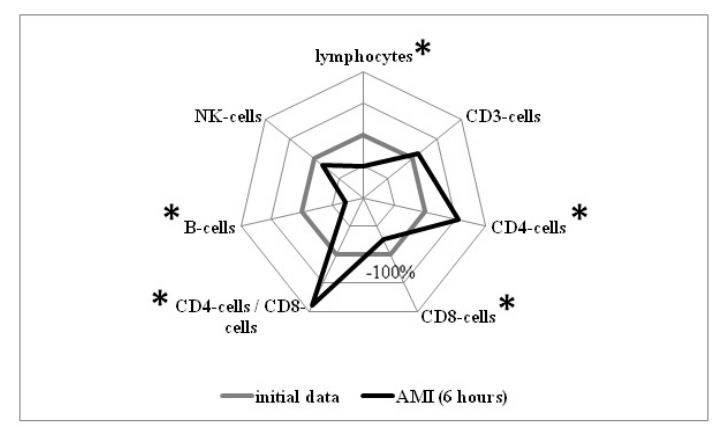

Fig. 2. Changes in blood lymphocyte populations after 6 hours of AMI (* - statistically significant differences compared to the initial data (values are taken as 100\%)).

After 8 hours of AMI development, more pronounced changes were observed concerning various populations of lymphocytes: a statistically significant decrease in the total number of lymphocytes by $65.4 \%(P<0.05), \mathrm{CD} 3+\mathrm{T}$ cells by $56.84 \%(P<0.05), \mathrm{CD} 4+\mathrm{T}$ cells by $38.38 \%(P<0.05), \mathrm{CD} 8+$ T cells by $80.56 \%(P<0.05)$, B cells by $89.03 \%(P<0.05)$, and NK cells by $68.36 \%(P<0.05)$ relative to the initial data. It should be noted that during this period, the $\mathrm{CD} 4+/ \mathrm{CD} 8+$ ratio increased by more than 3 times $(P<0.01)$ relative to the initial indicator (Fig. 3).

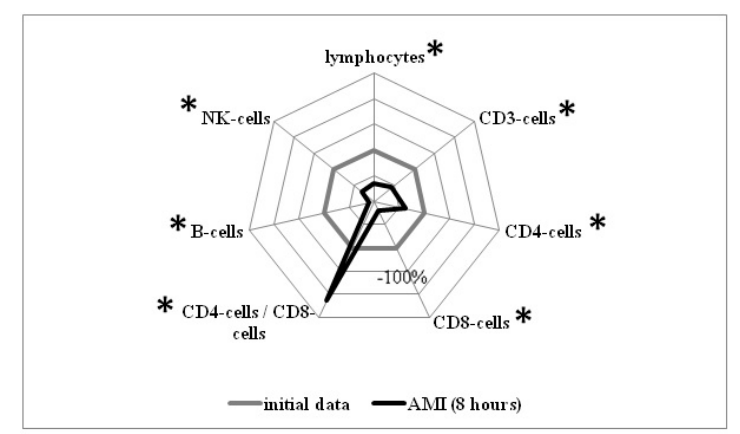

Fig. 3. Changes in blood lymphocyte populations after 8 hours of AMI (* - statistically significant differences compared to the initial data (values are taken as 100\%)).
The majority of all immunocompetent cells are localized in the intestinal mucosa, with the primary protective barrier being intraepithelial lymphocytes, represented mostly by cytotoxic CD8+ T cells. ${ }^{(10)}$ Although there is some territorial separation of the systemic immunity and the mucosaassociated lymphoid tissues, all the main groups of the immune system function as a whole, which is due to the unique ability of lymphocytes to migrate and recycle.

In the first three hours of AMI, we registered significant changes in cell-mediated immunity, which was expressed by an increase in the content of $\mathrm{CD} 3+\mathrm{T}$ cells (mature $\mathrm{T}$ lymphocytes), as well as their populations (CD4+ $\mathrm{T}$ cells and cytotoxic $\mathrm{CD} 8+\mathrm{T}$ cells). Immunocompetent cells are the main components of the immune system, which are actively involved in inflammatory reactions and the formation of the immune response. ${ }^{(12-15)}$ The participation of $\mathrm{T}$ lymphocytes in immune responses is due to the ability to recognize antigens. $\mathrm{CD} 3+\mathrm{T}$ cells regulate and form an effector immune response. ${ }^{(10)} \mathrm{An}$ increase in the number of CD4+ T cells can be observed in the T helper (Th2) type of immune response. Thus, the detected changes at the initial stage of ischemia may indicate an increase in the activity of immune processes, which occurs in the conditions of the pathological process development.

By the sixth hour of AMI, changes were generally similar to the previous period in the form of reduced values of the total number of lymphocytes, an increase in the level of CD4+ $\mathrm{T}$ cells and the $\mathrm{CD} 4+/ \mathrm{CD} 8+$ ratio. At the same time, a lower content of $\mathrm{CD} 8+\mathrm{T}$ cells and $\mathrm{B}$ cells relative to the initial data was registered, which indicates the development of secondary immunodeficiency in this period.

The eighth hour of ischemia was characterized by more pronounced changes in cellular immunity in the form of a decrease in the total number of lymphocytes, as well as all the studied subpopulations $(\mathrm{CD} 3+\mathrm{T}$ cells, $\mathrm{CD} 4+\mathrm{T}$ cells, $\mathrm{CD} 8+\mathrm{T}$ cells, B cells, and NK cells).

The mechanism of ischemic disorders in the intestine is mostly associated with impaired microcirculation, which ultimately leads to circulatory hypoxia of the intestinal wall. ${ }^{(8)}$ At the same time, enterocytes - the main cells of the intestinal mucosa - are most affected, which is facilitated by a decrease in the level of energy metabolism, activation of anaerobic glycolysis, and high activity of prooxidant factors. ${ }^{(5,8,16-19)}$ The changes in the activity of enzymes in hypoxia conditions lead to the destabilization of cell membranes and organelle membranes, which is manifested by a violation of their permeability, a violation of the ion pump operation, and intracellular electrolyte disorders. ${ }^{(20-22)}$ There is evidence of pronounced violations of intraepithelial contacts of the intestinal mucosa already at the beginning of total ischemia. (23) Against the background of progressive ischemia, the effects of microbial and tissue endotoxins are added, which leads to necrotic changes in the intestinal wall, with further perforation and peritonitis. ${ }^{(16)}$ Probably, the progressive dysregulation of the immune system can be explained by the presence of a massive translocation of intestinal microflora through broken intestinal barriers, along with the migration of lymphocytes to the lesion and their death on the background of acute ischemia. 
Thus, in conditions of AMI, a progressive decrease in the total number of venous blood lymphocytes with the development of an imbalance in their subpopulation occurs. Dysregulation of cellular immunity is directly related to the duration of intestinal ischemia and can be used as a predictor of the pathological condition severity.

\section{Competing Interests}

The authors declare that they have no competing interests.

\section{References}

1. Patel A, Kaleya RN, Sammartano RJ. Pathophysiology of mesenteric ischemia. Surg Clin North Am. 1992;72(1):31-41. doi:10.1016/s0039-6109(16)45626-4

2. Bala M, Kashuk J, Moore EE, Kluger Y, Biffl W, Gomes $\mathrm{CA}$, et al. Acute mesenteric ischemia: guidelines of the World Society of Emergency Surgery. World J Emerg Surg. 2017;12:38. Published 2017 Aug 7. doi:10.1186/s13017-017-0150-5

3. Florim S, Almeida A, Rocha D, Portugal P. Acute mesenteric ischaemia: a pictorial review. Insights Imaging. 2018;9(5):673-682. doi:10.1007/s13244-018-0641-2

4. Ranchordás S, Cunha C, Roque R, Féria L, Maio R. Acute mesenteric ischemia: a review of 50 cases. International Surgery Journal. 2019;6(7):2272-2278.

5. Liao G, Chen S, Cao H, Wang W, Gao Q. Review: Acute superior mesenteric artery embolism: A vascular emergency cannot be ignored by physicians. Medicine (Baltimore). 2019;98(6):e14446. doi:10.1097/MD.0000000000014446

6. Lim S, Halandras PM, Bechara C, Aulivola B, Crisostomo P. Contemporary Management of Acute Mesenteric Ischemia in the Endovascular Era. Vasc Endovascular Surg. 2019;53(1):42-50. doi:10.1177/1538574418805228

7. Bertoni S, Ballaben V, Barocell E, Tognolini M. Mesenteric ischemia-reperfusion: an overview of preclinical drug strategies. Drug Discov Today. 2018;23(7):1416-1425. doi:10.1016/j.drudis.2018.05.034

8. Khadaroo RG, Churchill TA, Tso V, Madsen KL, Lukowski C, Salim SY. Metabolomic profiling to characterize acute intestinal ischemia/reperfusion injury. PLoS One. 2017;12(6):e0179326. Published 2017 Jun 29. doi:10.1371/ journal.pone. 0179326

9. Klose CS, Artis D. Innate lymphoid cells as regulators of immunity, inflammation and tissue homeostasis. Nat Immunol. 2016;17(7):765-774. doi:10.1038/ni.3489

10. Zhang CX, Wang HY, Chen TX. Interactions between Intestinal Microflora/Probiotics and the Immune System. Biomed Res Int. 2019;2019:6764919. Published 2019 Nov 20. doi:10.1155/2019/6764919

11. Artamonova ZA, Namokonov EV, Tereshkov PP, Rusaeva NS. [Method for the diagnosis of intestinal necrosis in mesenteric ischemia in experiment]. Patent RU 2552338 C1, 10.06.2015. Application №. 2014110453/15 of 03.18.2014. [In Russian].
12. Kany S, Vollrath JT, Relja B. Cytokines in Inflammatory Disease. Int J Mol Sci. 2019;20(23):6008. Published 2019 Nov 28. doi:10.3390/ijms20236008

13. Kolesnikova LI, Kolesnikov SI, Romanova ED, Chkhenkeli VA, Darenskaya MA, Grebenkina LA, et al. Effect of Preparation Based on Trametes Pubescens Xylotroph Fungi on Lipid Peroxidation in the Blood of Experimental Animals under Conditions of Dark Stress. Bull Exp Biol Med. 2017;162(6):762-764. doi:10.1007/s10517-017-3707-0

14. Kolesnikova LI, Rychkova LV, Kolesnikova LR, Darenskaya MA, Natyaganova LV, Grebenkina LA, et al. Coupling of Lipoperoxidation Reactions with Changes in Arterial Blood Pressure in Hypertensive ISIAH Rats under Conditions of Chronic Stress. Bull Exp Biol Med. 2018;164(6):712-715. doi:10.1007/s10517-018-4064-3

15. Kolesnikova LI, Darenskaya MA, Kolesnikov SI. [Free radical oxidation: pathophysiologist's view]. Bulletin of Siberian medicine. 2017;16(4):16-29. [Article in Russian].

16. Korobkov DM. [Acute intestinal obstruction - a modern vision of developmental mechanisms and debate in the choice of diagnostic and therapeutic tactics]. Bulletin of Science and Practice. 2016;12(13):147-170. [Article in Russian]

17. Darenskaya MA, Grebenkina LA, Sholokhov LF, Rashidova MA, Semenova NV, Kolesnikov S.I., et al. Lipid peroxidation activity in women with chronic viral hepatitis. Free Radical Biology \& Medicine. 2016;100(S):S192.

18. Kolesnikova LI, Kolesnikov SI, Darenskaya MA, Grebenkina LA, Nikitina OA, Lazareva LM, et al. Activity of LPO Processes in Women with Polycystic Ovarian Syndrome and Infertility. Bull Exp Biol Med. 2017;162(3):320-322. doi:10.1007/s10517-017-3605-5

19. Kolesnikova LI, Kolesnikova LR, Darenskaya MA, Natyaganova LV, Grebenkina LA, Korytov LI, et al. Evaluation of Lipid Peroxidation-Antioxidant Defense System Depending on the Stage of Stress Reaction in Hypertensive ISIAH Rats. Bull Exp Biol Med. 2019;166(5):610-612. doi:10.1007/ s10517-019-04402-6

20. Kolesnikova LR, Darenskaya MA, Rychkova LV, Pogodina AV, Grebenkina LA, Kolesnikov SI, et al. Oxidative stress parameters and state of regional periodontal blood flow in adolescents with arterial hypertension and periodontal diseases. International Journal of Biomedicine. 2018;8(4):301305. doi:10.21103/Article8(4)_OA6

21. Darenskaya MA, Kolesnikov SI, Rychkova LV, Grebenkina LA, Kolesnikova LI. Oxidative stress and antioxidant defense parameters in different diseases: ethnic aspects. Free Radical Biology \& Medicine. 2018;120(S1):60.

22. Bairova TA, Kolesnikov SI, Kolesnikova LI, Pervushina OA, Darenskaya M.A, Grebenkina LA. Lipid peroxidation and mitochondrial superoxide dismutase-2 gene in adolescents with essential hypertension. Bull Exp Biol Med. 2014;158(2):181-184. doi:10.1007/s10517-014-2717-4

23. Khripun AI, Shurygin SN, Mironkov AB, Izvekov AA, Guseva TV, Pryamikov AD. Microcirculation in the small and large intestine with thrombosis and thromboembolism of the mesenteric arteries. Surgery. Journal them. N.I. Pirogov. 2011;9:27-32. [In Russian]. 